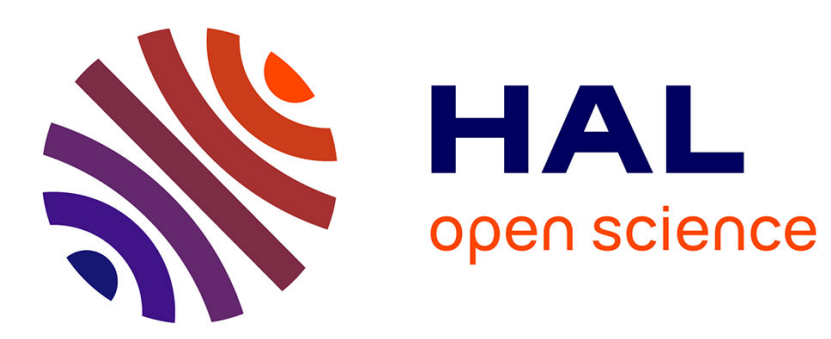

\title{
Ice melting and downward transport of meltwater by two-phase flow in Europa's ice shell
}

Klara Kalousova, Ondřej Souček, Gabriel Tobie, Gaël Choblet, Ondřej Čadek

\section{To cite this version:}

Klara Kalousova, Ondřej Souček, Gabriel Tobie, Gaël Choblet, Ondřej Čadek. Ice melting and downward transport of meltwater by two-phase flow in Europa's ice shell. Journal of Geophysical Research. Planets, 2014, 119 (3), pp.532-549. 10.1002/2013JE004563 . hal-02556607

\section{HAL Id: hal-02556607 https://hal.science/hal-02556607}

Submitted on 4 Jan 2022

HAL is a multi-disciplinary open access archive for the deposit and dissemination of scientific research documents, whether they are published or not. The documents may come from teaching and research institutions in France or abroad, or from public or private research centers.
L'archive ouverte pluridisciplinaire HAL, est destinée au dépôt et à la diffusion de documents scientifiques de niveau recherche, publiés ou non, émanant des établissements d'enseignement et de recherche français ou étrangers, des laboratoires publics ou privés.

$$
\text { Copyright }
$$




\section{Journal of Geophysical Research: Planets}

\author{
RESEARCH ARTICLE \\ 10.1002/2013JE004563 \\ Key Points: \\ - We model water-ice mixture in \\ 1-D considering different tidal \\ heating scenarios \\ - We show that water above a hot ice \\ plume is not stable \\ - Large amount of water may tem- \\ porarily accumulate below a \\ strike-slip fault
}

Correspondence to:

K. Kalousová,

kalous@karel.troja.mff.cuni.cz

\section{Citation:}

Kalousová, K., O. Souček, G. Tobie, G. Choblet, and O. Čadek (2014), Ice melting and downward transport of meltwater by two-phase flow in Europa's ice shell, J. Geophys. Res. Planets, 119, 532-549, doi:10.1002/2013JE004563.

Received 18 OCT 2013 Accepted 13 FEB 2014 Accepted article online 17 FEB 2014 Published online 11 MAR 2014

\section{Ice melting and downward transport of meltwater by two-phase flow in Europa's ice shell}

\author{
Klára Kalousová ${ }^{1,2}$, Ondřej Souček ${ }^{1,3}$, Gabriel Tobie ${ }^{1}$, Gaël Choblet ${ }^{1}$, and Ondřej Čadek ${ }^{2}$ \\ ${ }^{1}$ Laboratoire de Planétologie et Géodynamique, Université de Nantes, CNRS, UMR 6112, Nantes, France, ${ }^{2}$ Department of \\ Geophysics, Faculty of Mathematics and Physics, Charles University, Prague, Czech Republic, ${ }^{3}$ Mathematical Institute, \\ Faculty of Mathematics and Physics, Charles University, Prague, Czech Republic
}

Abstract With its young surface, very few impact craters, and the abundance of tectonic and cryovolcanic features, Europa has likely been subjected to relatively recent endogenic activity. Morphological analyses of chaos terrains and double ridges suggest the presence of liquid water within the ice shell a few kilometers below the surface, which may result from enhanced tidal heating. A major issue concerns the thermal/ gravitational stability of these water reservoirs. Here we investigate the conditions under which water can be generated and transported through Europa's ice shell. We address particularly the downward two-phase flow by solving the equations for a two-phase mixture of water ice and liquid water in one-dimensional geometry. In the case of purely temperate ice, we show that water is transported downward very efficiently in the form of successive porosity waves. The time needed to transport the water from the subsurface region to the underlying ocean varies between $\sim 1$ and $100 \mathrm{kyr}$, depending mostly on the ice permeability. We further show that water produced in the head of tidally heated hot plumes never accumulates at shallow depths and is rapidly extracted from the ice shell (within less than a few hundred kiloyears). Our calculations indicate that liquid water will be largely absent in the near subsurface, with the possible exception of cold conductive regions subjected to strong tidal friction. Recently active double ridges subjected to large tidally driven strike-slip motions are perhaps the most likely candidates for the detection of transient water lenses at shallow depths on Europa.

\section{Introduction}

Europa has a strikingly young surface with a few impact craters and very abundant tectonic and cryovolcanic features pointing to relatively recent endogenic activity [e.g., Pappalardo et al., 1998; Carr et al., 1998; Bierhaus et al., 2009; Kattenhorn and Hurford, 2009; Collins and Nimmo, 2009]. The gravity data collected by the Galileo spacecraft indicate that the satellite interior is differentiated into a metallic core, a silicate mantle and an outer $\mathrm{H}_{2} \mathrm{O}$ layer [Anderson et al., 1998]. The detection of an induced magnetic field further indicates that Europa possesses a global salty ocean underneath the outer ice shell [Kivelson et al., 2000]. Nevertheless, the current thickness of the ice shell as well as its thermal state still remain unconstrained.

At present, the thermal regime in the ice shell may be either conductive or convective [e.g., Barr and Showman, 2009], and the associated thickness may vary between less than $10 \mathrm{~km}$ and more than $40 \mathrm{~km}$. The thermal state depends mostly on the ice shell thickness and viscosity, determining the critical Rayleigh number of the system [McKinnon, 1999; Barr and Pappalardo, 2005]. Unfortunately, no observations allowing a robust estimate of the viscosity structure and the shell thickness are available. Various features observed at the surface may be compatible with a brittle-elastic lithosphere (1-2 km thick) above a ductile and possibly convecting layer in the time of formation [e.g., Pappalardo et al., 1999], but it is uncertain whether the ice shell has remained in this state until present.

Recent morphological analyses of chaos terrains [Schmidt et al., 2011] and double ridges [Dombard et al., 2013] suggest the presence of liquid water within the ice shell in the form of lenses or sills a few kilometers below the surface. However, these interpretations are still subject to debate and it is not clear if liquid water can accumulate in the upper part of Europa's ice shell. The meltwater production at shallow depth may be the consequence of enhanced tidal heating, expected either in thermal hot plumes due to thermally reduced viscosity [e.g., Sotin et al., 2002; Tobie et al., 2003; Běhounková et al., 2010] or along faults due to tidally activated strike-slip motions [e.g., Gaidos and Nimmo, 2000; Nimmo and Gaidos, 2002]. While the 
former mechanism requires the ice shell to be in a convective regime, the latter is rather insensitive to the thermal state as it is localized in the coldest (brittle) part of the layer along the faults and at the transition between the brittle and the ductile layer [Nimmo and Gaidos, 2002]. Regardless of the source of heating, a major issue concerns the thermal and gravitational stability of these perched water reservoirs: due to the higher density of water relative to the surrounding ice, these reservoirs should be drained rather rapidly [e.g., Nimmo and Giese, 2005].

Reliable estimates of the efficiency of this drainage process require rather detailed knowledge of the hydrological network within the layer. In glaciers on the Earth, such hydrological networks play a key role in the water transport and undergo annually a very complex spatial-temporal evolution [e.g., Irvine-Fynn et al., 2011]. After the onset of melting season, the enhanced solar radiation provides an increasing amount of meltwater, leading to gradual development of a supraglacial hydrological system [e.g., Fountain and Walder, 1998]. Water flowing to lower altitudes gets eventually captured in surface-reaching crevasses which, when sufficiently supplied, tend to propagate downward by a combination of hydrofracturing and/or frictional downcutting. By these mechanisms, the crevasses can penetrate all the way to the glacier base and establish an efficient hydrological connection between the surface and the basal drainage system, promoting rapid water transfer to the base of the glacier [e.g., Fountain and Walder, 1998].

The physical setting within the ice shell of Europa differs from that on the Earth in several aspects. Since the outer ice shell is underlain by a global water ocean, the subglacial drainage system - perhaps the most complex part of the hydrological network in terrestrial glaciers-is completely missing. In addition, due to the very low surface temperatures $(\sim 100 \mathrm{~K})$, the hydrological network-if any-is effectively closed from above. All the melt would be produced in the bulk, a few kilometers below the surface, where hydrofracturing is less likely-the overburden pressure in the interior of the shell probably maintains the ice in compressional regime and thus limits crack initiation. Even if cracks develop, the estimated meltwater production rates are smaller by few orders of magnitude compared to the terrestrial supply during the melting season: For frictional heat generation rate at the fault of $10^{-4} \mathrm{~W} \mathrm{~m}^{-3}$ [Nimmo and Gaidos, 2002] and for the fault thickness of the order of $10^{3} \mathrm{~m}$, the estimated surface heat flux is $\sim 10^{-1} \mathrm{~W} \mathrm{~m}^{-2}$, which is significantly smaller than typical values obtained for Alpine glaciers $\left(\sim 10^{1}-10^{2} \mathrm{~W} \mathrm{~m}^{-2}\right.$ [e.g., Hock, 2005]). The resulting meltwater supply might thus be insufficient to feed the crevasses by appropriate amount of meltwater required for hydrofracturing across the whole ice layer, particularly if refreezing is efficient. Besides, the thickness of the ice shell is 1 order of magnitude larger than that of the biggest terrestrial glaciers.

Provided the hydrological system is closed from above, the downward meltwater drainage through the ice shell must be simultaneously compensated by an accompanying ice flow since the overburden pressure rules out voids. The two phases are thus strongly mechanically coupled and neither Fick's nor traditional Darcy's law, often used to describe the terrestrial englacial water transport, can properly describe the water flow through the ice matrix. For partially molten (temperate) ice, the problem is rather similar to silicate magma generation and its transport through the Earth's mantle and can be handled by the same theoretical framework-the two-phase formalism.

The two-component (or, generally, multicomponent) formalisms have been applied to various geophysical problems-besides magma generation and its subsequent flow [e.g., McKenzie, 1984; Spiegelman and McKenzie, 1987] also in modeling the formation of planetary cores [e.g., Ricard et al., 2009; Šrámek et al., 2010] or in soil mechanics [e.g., Birchwood and Turcotte, 1994]. As the problem is rather complicated per se, several approximations have been introduced, such as "small porosity approximation" [e.g., Connolly and Podladchikov, 2007] or "zero compaction length approximation" [e.g., Scott and Stevenson, 1989; Spiegelman, 1993a, 1993b], with the latter neglecting the effect of matrix deformation on melt flow. Since we cannot a priori rule out the significance of this effect, we include it in our application.

The key parameter in two-phase flow modeling is the permeability, i.e., the ability of a material to transmit fluids. In many two-phase applications, permeability is assumed to be a simple power law function of porosity $\phi$ with the exponent typically between 2 and 3 [e.g., McKenzie, 1984; Scott and Stevenson, 1984; Spiegelman, 1993b; Rabinowicz et al., 2002; Šrámek et al., 2007]. Ice permeability generally depends on numerous state and material parameters, such as the geometric properties of the pore system (pore diameter and tortuosity of the path), pressure in the liquid, temperature and composition (salinity, presence of ammonia, etc.), deformation history, etc. [e.g., Lliboutry, 1996; Petrich et al., 2006; Golden et al., 2006, 2007; Petrich and Eicken, 2009]. Depending on the physical context and growth mechanisms of ice crystals, 


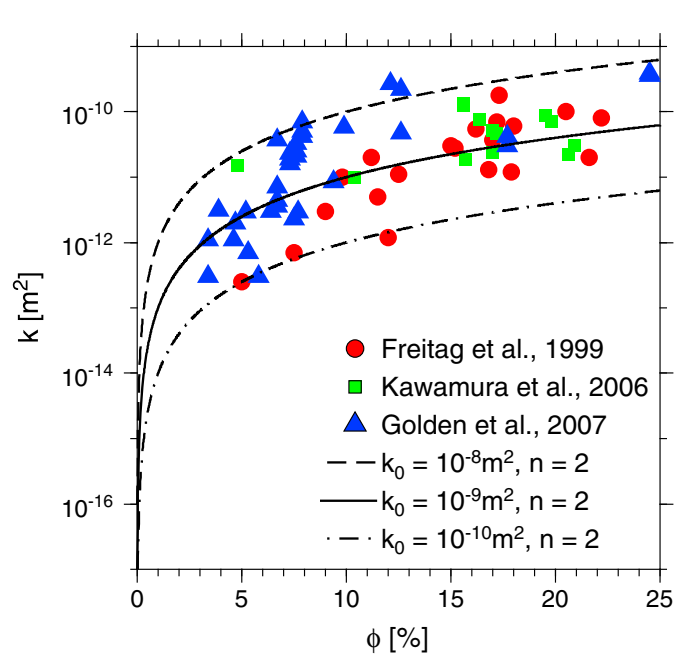

Figure 1. Comparison of measured values of ice permeability (colored symbols) with the theoretical curves considered in this work (black lines). Measured values have been read from figures in Freitag [1999], Kawamura et al. [2006], and Golden et al. [2007]. ice permeability may also exhibit anisotropy [Freitag and Eicken, 2003] and it may abruptly decrease for very small porosities, which is sometimes parameterized by the so-called "percolation threshold" [Golden et al., 1998]. Measurements of ice permeability reveal variations over several orders of magnitude [e.g., Freitag, 1999; Eicken et al., 2002; Freitag and Eicken, 2003; Kawamura et al., 2006; Golden et al., 2007]. In our model, we consider scalar (isotropic) permeability in the form $k(\phi)=k_{0} \phi^{2}$ and include the uncertainty in magnitude by varying $k_{0}$ accordingly in order to capture the whole range of admissible situations. Figure 1 compares the measured values of ice permeability with the theoretical curves obtained for three values of $k_{0}\left(10^{-8}, 10^{-9}\right.$, and $\left.10^{-10} \mathrm{~m}^{2}\right)$, considered in this study. While we use the middle value $\left(10^{-9} \mathrm{~m}^{2}\right)$ in section 3 to compute the reference solution, the smallest value $\left(10^{-10} \mathrm{~m}^{2}\right)$ is used in section 4 , where it provides the lower bound on permeability and thus the upper bound on the extraction timescale.

As mentioned above, on Europa, there are two typical geodynamical contexts for which liquid water may be produced and possibly accumulated: chaos terrains and strike-slip faults. The crucial question concerns the stability of shallow partially molten or even liquid regions, their depth and the time needed to extract liquid water from the shallow subsurface or to freeze it. The aim of this paper is to answer this question by developing a two-phase model of Europa's ice shell. Several studies have addressed the problem of water transport in the ice shell, both the gravity-driven downward propagation [e.g., Běhounková et al., 2012] and possible overpressure-induced upward flow [e.g., Crawford and Stevenson, 1988; Showman et al., 2004; Manga and Wang, 2007; Michaut and Manga, 2014]. But, to our knowledge, no study has applied the two-phase flow formalism and modeled the interactions between liquid and solid phases in the present complexity. The problem is challenging from the numerical point of view and, as a first step, we solve it in a one-dimensional Cartesian geometry. Although this approach represents an enormous simplification, it provides a first-order estimate of the rate of water transport in the outer shell of Europa.

In the next sections, we briefly describe the numerical method (section 2) and the results obtained from simulations for a layer of partially molten (temperate) ice (section 3 ) and for a more realistic case of polythermal ice (section 4). We discuss the approximations used in our model and their possible effect on our results in section 5 . Finally, the implications of our results for the dynamics of Europa's ice shell are summarized in section 6 .

\section{Numerical Model}

The melting point of water ice is uniquely determined by pressure, temperature, and composition. Since we consider the material to be pure water ice (containing no impurities), the state variables reduce to pressure and temperature. For given pressure-temperature conditions, ice can be present in two different states-temperate ice where temperature equals the melting temperature $\left(T=T_{\mathrm{M}}\right)$ and some amount of interstitial liquid water is present (porosity $\phi>0$ ) and cold ice characterized by ice temperature below the melting point $\left(T<T_{M}\right)$ and zero liquid water content $(\phi=0)$. The evolution of these two variables-porosity $\phi$ and temperature $T$-determines locally in which of the two states the ice is present, and thus which equations govern its dynamics. While in the former case (temperate ice), a two-phase formalism must be adopted in order to capture the dynamical coupling between the phases, in the latter case (cold ice), the governing equations reduce to the standard continuum balance equations for a single phase. The ice body is called polythermal if both regions (cold and temperate) are simultaneously present [e.g., Irvine-Fynn et al., 2011]. 


\subsection{Governing Equations for Temperate Ice}

To model the transport of heat and liquid water within the ice shell of Europa, we employ the multiphase formalism and apply it to a mixture of two incompressible fluids. Our approach follows closely the work of Drew [1971, 1983], Bercovici et al. [2001], and Šrámek et al. [2007], whose formalism is adapted for the particular case of a water ice-liquid water mixture. The system comprises five equations-two mass balances (one for each phase), two linear momentum balances (again one for each phase), and one energy balance for the mixture as a whole. This simplification of the energy balance is enabled by the assumption of a common (equilibrium phase change) temperature for both phases.

After introducing appropriate scales, the original equations were rewritten in a nondimensional form and the governing dimensionless numbers were identified and evaluated using the physical parameters appropriate to our problem. Based on this analysis, we neglected several terms of minor physical significance, namely, the inertial forces, the momentum transfer due to melting/freezing, viscous stresses in the fluid phase, all terms containing surface tension and the deformational work of both phases.

We now present the final system of governing equations in one-dimensional Cartesian geometry, obtained by considering only vertical motion and vertical dependence of all quantities. The fluid mass balance reads

$$
\frac{\partial \phi}{\partial t}+\frac{\partial}{\partial z}\left(\phi\left(v_{\mathrm{r}}+v_{\mathrm{m}}\right)\right)=\frac{r_{\mathrm{f}}}{\rho_{\mathrm{f}}},
$$

where $\phi$ denotes the porosity, $t$ denotes the time, $z$ is the vertical coordinate (oriented upward and ranging from 0 to $D$, which is the thickness of the ice shell), $v_{\mathrm{r}}=v_{\mathrm{f}}-v_{\mathrm{m}}$ is the relative velocity of water with respect to ice, $r_{\mathrm{f}}$ is the melt production rate (positive for melting) and $\rho_{\mathrm{f}}$ is the water density (assumed constant). Throughout this paper, we assume that the water-ice mixture is saturated-porosity $\phi$ then corresponds to the liquid water volume fraction (and should not thus be confused with the air content). The ice matrix mass balance takes the form

$$
\left.-\frac{\partial \phi}{\partial t}+\frac{\partial}{\partial z}\left((1-\phi) v_{m}\right)\right)=-\frac{r_{f}}{\rho_{m}},
$$

where $\rho_{\mathrm{m}}$ is the ice density (assumed constant).

The linear momentum balance for the fluid can be written in the form corresponding to Darcy's law

$$
c(\phi) v_{\mathrm{r}}=-\phi\left(\frac{\partial \Pi}{\partial z}+\Delta \rho g\right) .
$$

Here $c(\phi)$ is the drag coefficient defined by

$$
c(\phi)=\frac{\mu_{\mathrm{f}} \phi^{2}}{k(\phi)},
$$

where $\mu_{\mathrm{f}}$ is the shear viscosity of water and $k(\phi)$ is the ice permeability given by

$$
k(\phi)=k_{0} \phi^{n},
$$

where $k_{0}$ and $n$ are the permeability constant and exponent, respectively. The excess water pressure $\Pi$ is defined as $\Pi=P_{\mathrm{f}}-P_{\mathrm{m}}^{\text {ref }}$, where $P_{\mathrm{f}}$ denotes the water pressure and $P_{\mathrm{m}}^{\text {ref }}$ the reference hydrostatic pressure (corresponding to pure ice). The density difference $\Delta \rho$ is defined as $\Delta \rho=\rho_{\mathrm{m}}-\rho_{\mathrm{f}}$, and $g$ is the gravity acceleration.

The linear momentum balance for matrix reads

$$
(1-\phi) \frac{\partial \Pi}{\partial z}=c(\phi) v_{\mathrm{r}}+\frac{\partial}{\partial z}\left[(1-\phi)\left(\frac{4}{3} \mu_{\mathrm{m}} \frac{\partial v_{\mathrm{m}}}{\partial z}-\Delta P\right)\right],
$$

where $\mu_{\mathrm{m}}$ is the ice shear viscosity and the pressure difference $\Delta P$ is defined as $\Delta P=P_{\mathrm{m}}-P_{\mathrm{f}}$ with $P_{\mathrm{m}}$ being the ice pressure. Assuming that $\mu_{\mathrm{f}} \ll \mu_{\mathrm{m}}$, the pressure difference can be written as [Šrámek et al., 2007]

$$
\Delta P=-\frac{\mu_{0} \mu_{\mathrm{m}}}{\phi} \frac{\partial v_{\mathrm{m}}}{\partial z}
$$

where $\mu_{0}$ is a dimensionless parameter, $\mu_{0} \sim 1$ [Bercovici et al., 2001]. The expression $\mu_{0} \mu_{\mathrm{m}} / \phi \sim \mu_{\mathrm{m}} / \phi$ can be interpreted as a bulk viscosity [cf. Ricard et al., 2001]. 
Adding the two mass balances (1) and (2) and substituting for $v_{\mathrm{r}}$ from (3), for $\partial \Pi / \partial z$ from (6) and for $\Delta P$ from (7) leads to the following equation for the matrix velocity $v_{m}$ :

$$
\frac{\partial v_{\mathrm{m}}}{\partial z}-\frac{\partial}{\partial z}\left\{\frac{\phi^{2}}{c(\phi)} \frac{\partial}{\partial z}\left[(1-\phi) \mu_{\mathrm{m}}\left(\frac{1}{\phi}+\frac{4}{3}\right) \frac{\partial v_{\mathrm{m}}}{\partial z}\right]\right\}=-\frac{\partial}{\partial z}\left(\frac{\phi^{2}}{c(\phi)}(1-\phi) \Delta \rho g\right)+\frac{\Delta \rho}{\rho_{\mathrm{f}} \rho_{\mathrm{m}}} r_{\mathrm{f}} .
$$

Furthermore, combining equations (3) and (6), we obtain the linear momentum balance for the fluid phase in the following form:

$$
c(\phi) v_{\mathrm{r}}=\phi(1-\phi) \Delta \rho g-\phi \frac{\partial}{\partial z}\left[(1-\phi) \mu_{\mathrm{m}}\left(\frac{1}{\phi}+\frac{4}{3}\right) \frac{\partial v_{\mathrm{m}}}{\partial z}\right] .
$$

Equation (9) expresses the balance of the drag force (left-hand side), the gravitational force (first term on the right-hand side) and the force induced by mechanical coupling between the deformation of the ice matrix and the movement of liquid water through the ice matrix (second term on the right-hand side). Note that in this one-dimensional setting, we have completely eliminated the excess water pressure $\Pi$ from the system and reduced the number of equations accordingly.

The energy balance within temperate ice can be simplified by a natural assumption of thermodynamic equilibrium between the phases. The temperature of both water and ice is then given by the melting temperature $T_{M}$, and the energy balance for the ice-water mixture as a whole reduces to the following equation for the melting rate $r_{\mathrm{f}}$ :

$$
L r_{\mathrm{f}}=-\phi \rho_{\mathrm{f}} c_{\mathrm{f}}\left(v_{\mathrm{r}}+v_{\mathrm{m}}\right) \frac{\partial T_{\mathrm{M}}}{\partial z}-(1-\phi) \rho_{\mathrm{m}} c_{\mathrm{m}} v_{\mathrm{m}} \frac{\partial T_{\mathrm{M}}}{\partial z}+H+\frac{\partial}{\partial z}\left(k^{\top}(\phi) \frac{\partial T_{\mathrm{M}}}{\partial z}\right)+c(\phi)\left|v_{\mathrm{r}}\right|^{2} .
$$

Here $c_{\mathrm{f}}$ and $c_{\mathrm{m}}$ are the heat capacities of water and ice, respectively, $L$ is the latent heat of melting of ice, $H$ is the volumetric heating, and $k^{\top}(\phi)$ is the heat conductivity of the mixture. The melting rate on the left-hand side of equation (10) is controlled by the following processes on the right-hand side: heat advection (the first two terms), volumetric heating (third term), conductive heat transfer (fourth term), and frictional heating due to the water movement in the ice matrix (last term). The ice-water melting temperature $T_{\mathrm{M}}$ at a given ice matrix pressure $P_{\mathrm{m}}$ can be expressed as [Simon and Glatzel, 1929]:

$$
T_{\mathrm{M}}\left(P_{\mathrm{m}}\right)=T_{0}\left(\frac{P_{\mathrm{m}}-P_{0}}{a}+1\right)^{\frac{1}{b}},
$$

where $T_{0}$ denotes the melting temperature at reference pressure $P_{0}$ and $a, b$ the empirical constants (with values taken from Chizhov [1993]). Since we neglect the dynamic pressure effects on $T_{M}$, it varies only with depth and is constant in time. Note that the role of temperature is taken over by the porosity $\phi$, since the energy is now "stored" in latent heat. Heat conductivity $k^{\top}(\phi)$ is considered in the form (linearization of McKenzie [1984])

$$
k^{\top}(\phi)=k_{m}^{\top}\left(1-3 \phi \frac{k_{m}^{\top}-k_{f}^{\top}}{2 k_{m}^{\top}+k_{f}^{\top}}\right),
$$

where $k_{\mathrm{m}}^{\top}$ and $k_{\mathrm{f}}^{\top}$ are the heat conductivities of pure ice and pure water, respectively.

\subsection{Governing Equations for Cold Ice}

The cold ice (if not significantly fractured) is essentially impermeable [e.g., Gusmeroli et al., 2010], and thus, $\phi=0$. Mass balance (equation of continuity) then reads

$$
\frac{\partial v_{m}}{\partial z}=0
$$

and thus, in a one-dimensional setting, ice velocity $v_{\mathrm{m}}$ is constant in space. The linear momentum balance reduces to the condition of hydrostatic equilibrium

$$
\frac{\partial P_{\mathrm{m}}}{\partial z}=-\rho_{\mathrm{m}} g
$$

The melting rate $r_{\mathrm{f}}$ is by definition zero, and the energy balance is given by the standard heat equation for unknown temperature $T$ :

$$
\rho_{\mathrm{m}} c_{\mathrm{m}}\left(\frac{\partial T}{\partial t}+v_{\mathrm{m}} \frac{\partial T}{\partial z}\right)=k_{\mathrm{m}}^{\top} \frac{\partial^{2} T}{\partial z^{2}}+H
$$




\subsection{Boundary Conditions}

For both cases studied in section 4, we consider the following boundary conditions for temperature

$$
\begin{aligned}
& \left.T\right|_{z=D, t}=T_{\mathrm{s}}, \\
& \left.T\right|_{z=0, t}=\left.T_{\mathrm{M}}\right|_{z=0},
\end{aligned}
$$

where $T_{\mathrm{s}}$ denotes the surface temperature and $\left.T_{M}\right|_{z=0}$ is the melting temperature at the base of the ice shell which is considered to be the interface with the internal ocean. In section 3 , we deal with a temperate ice and no boundary condition for $T$ is needed.

Concerning the mechanical boundary conditions, we prescribe zero matrix velocity (no-slip) at the bottom boundary:

$$
\left.v_{\mathrm{m}}\right|_{z=0, t}=0 .
$$

This boundary condition is to be viewed as a kinematic rather than dynamic boundary condition, as it basically serves to fix the reference frame in such a way that the bottom boundary of the ice layer does not move. This is a legitimate choice if one assumes that no significant surface melting occurs at this boundary. A physically more appropriate boundary condition would be a Neumann-type condition of equality of traction forces, which would, however, require determination of the water pressure below the ice layer. At the top boundary, we consider free surface condition, which in the 1-D setting and with surface pressure set to zero, reduces to

$$
\left.\frac{\partial v_{\mathrm{m}}}{\partial z}\right|_{z=D, t}=0
$$

As to the water transport, owing to an underlying water reservoir, we prescribe a free flux condition at the bottom boundary [cf. Spiegelman, 1993a]

$$
\left.\frac{\partial}{\partial z}\left[(1-\phi) \mu_{\mathrm{m}}\left(\frac{1}{\phi}+\frac{4}{3}\right) \frac{\partial v_{\mathrm{m}}}{\partial z}\right]\right|_{z=0, t}=0 .
$$

This condition corresponds to the water outflow from the domain that is mechanically uncoupled from the matrix deformation (cf. equation (9) in which equation (19) sets the last term on the right-hand side equal to zero).

When the uppermost part of the domain is temperate (only in section 3), we must prescribe porosity $\phi$ at the top boundary. Since we do not consider any source of liquid water above the ice shell, we set

$$
\left.\phi\right|_{z=D, t}=0 \text {. }
$$

\subsection{Numerical Method}

The nonlinear hyperbolic partial differential equation for porosity advection (1) is solved by a Total-Variation-Diminishing scheme, in particular by the Essentially Non-Oscillatory scheme [Shu, 1998]. Since the Essentially Non-Oscillatory schemes require an explicit in time discretization, the time stepping is severely constrained by the Courant-Friedrichs-Lewy (CFL) stability condition.

The third-order nonlinear partial differential equation for matrix velocity $v_{m}(8)$ is reformulated as a second-order equation for an auxiliary variable $\xi \equiv(1-\phi) \frac{\partial v_{m}}{\partial z}$, which is solved in the weak sense by the finite element method-here we employ piecewise linear approximation of $\xi$ for simplicity; $v_{m}$ is then reconstructed from $\xi$ by numerical quadrature. Relatively high spatial resolution is required in order to reach sufficient accuracy, which combined with the CFL condition leads to rather short time stepping.

The method of solution described above was numerically implemented and carefully tested. As shown in previous studies, the solution of governing equations for gravity-driven two-phase flow results in downward propagation of porosity waves [e.g., Scott and Stevenson, 1984; Scott et al., 1986; Olson and Christensen, 1986; Spiegelman, 1993a]. The wavelength of these waves increases with the so-called "compaction length" [e.g., Rabinowicz et al., 2002], defined as [McKenzie, 1984]

$$
\delta=\sqrt{\frac{k(\phi)\left(\zeta+\frac{4}{3} \mu_{\mathrm{m}}\right)}{\mu_{\mathrm{f}}}},
$$




\begin{tabular}{|c|c|c|c|}
\hline Symbol & Variable & Value & Unit \\
\hline$a$ & constant in melting temperature equation & -395.2 & $\mathrm{MPa}$ \\
\hline$b$ & constant in melting temperature equation & 9 & - \\
\hline$c_{\mathrm{f}}$ & heat capacity of water ${ }^{a}$ & 4180 & $\mathrm{~J}(\mathrm{~kg} \mathrm{~K})^{-1}$ \\
\hline$c_{\mathrm{m}}$ & heat capacity of ice ${ }^{a}$ & 2100 & $\mathrm{~J}(\mathrm{~kg} \mathrm{~K})^{-1}$ \\
\hline$|\Delta \rho|$ & density difference ${ }^{a}$ & 80 & $\mathrm{~kg} \mathrm{~m}^{-3}$ \\
\hline$E_{\mathrm{a}}$ & activation energy & 50 & $\mathrm{~kJ} \mathrm{~mol}^{-1}$ \\
\hline$g$ & surface gravity & 1.32 & $\mathrm{~m} \mathrm{~s}^{-2}$ \\
\hline$\gamma_{\mathrm{m}}$ & viscosity exponent & 45 & - \\
\hline$k_{0}$ & permeability constant & $10^{-9}$ & $m^{2}$ \\
\hline$k_{f}^{\top}$ & water thermal conductivity ${ }^{a}$ & 0.56 & $W(m ~ K)^{-1}$ \\
\hline$k_{\mathrm{m}}^{\dagger}$ & ice thermal conductivity ${ }^{\mathrm{a}}$ & 2.3 & $W(m K)^{-1}$ \\
\hline L & latent heat of melting of ice ${ }^{a}$ & 333 & $\mathrm{~kJ} \mathrm{~kg}^{-1}$ \\
\hline$\mu_{\mathrm{f}}$ & water shear viscosity ${ }^{a}$ & $1.793 \times 10^{-3}$ & Pas \\
\hline$\mu_{\mathrm{m}}$ & ice shear viscosity ${ }^{a}$ & $10^{14}$ & Pa s \\
\hline$n$ & permeability exponent & 2 & - \\
\hline$P_{0}$ & reference pressure & 0 & $\mathrm{~Pa}$ \\
\hline$D$ & Europa's ice shell thickness & 30 & $\mathrm{~km}$ \\
\hline$\rho_{\mathrm{f}}$ & water density ${ }^{\mathrm{a}}$ & 1000 & $\mathrm{~kg} \mathrm{~m}^{-3}$ \\
\hline$\rho_{\mathrm{m}}$ & ice density ${ }^{a}$ & 920 & $\mathrm{~kg} \mathrm{~m}^{-3}$ \\
\hline$T_{0}$ & ice melting temperature at $P_{0}$ & 273.15 & $\mathrm{~K}$ \\
\hline
\end{tabular}

where $\zeta$ is the bulk viscosity of ice, here taken as in Ricard et al. [2001] ( $\sim \mu_{\mathrm{m}} / \phi$, cf. text below equation (7)). In order to test our numerical method we compare the propagation velocity of porosity waves from the numerical solution with the analytically computed value in a purely mechanical setting (neglecting melting, i.e., $r_{\mathrm{f}}=0$, and ignoring the energy balance 10). Following the approach of Rabinowicz et al. [2002], we derive the analytical formula for porosity waves phase velocity assuming that $(1-\phi) \sim 1$

$$
c_{\mathrm{w}}^{\mathrm{A}}=\phi_{\min } \frac{k_{0} \Delta \rho g}{\mu_{\mathrm{f}}} \frac{\ln (r)+\frac{4}{3}\left(\phi_{\max }-\phi_{\min }\right)(r-1)-\frac{1}{2}\left(r^{2}-1\right)}{\frac{4}{3} \phi_{\min } \ln (r)+\left(1-\frac{4}{3} \phi_{\min }\right)(r-1)-\frac{1}{2}\left(r^{2}-1\right)},
$$

where $\phi_{\min }$ and $\phi_{\max }$ are the minimum and maximum values of porosity, respectively, and $r=\phi_{\min } / \phi_{\max }$. The other parameters are defined in Table 1. For the following initial condition:

$$
\Phi(z, 0)= \begin{cases}\Phi_{1} & z>z_{0} \\ \Phi_{0}+\left(\Phi_{1}-\Phi_{0}\right) \operatorname{sech}\left(\frac{z-z_{0}}{\lambda}\right) & z \leq z_{0}\end{cases}
$$

with $\lambda=14 \delta, z_{0}=950 \delta, \Phi_{1}=5 \%$, and $\Phi_{0}=2.5 \%$, the maximum and minimum values of porosity at the end of our simulation are $\phi_{\max }=8.4 \%$ and $\phi_{\min }=2.5 \%$ which give the wave velocity $c_{\mathrm{w}}^{\mathrm{A}}=-4.53 \times$ $10^{-6} \mathrm{~m} \mathrm{~s}^{-1}$. The wave velocity obtained numerically from our simulation is $c_{w}^{N}=-4.03 \times 10^{-6} \mathrm{~m} \mathrm{~s}^{-1}$. The agreement between the analytical and numerical values of velocity, $c_{w}^{A}$ and $c_{w^{\prime}}^{N}$, respectively, is similar to that reported in Rabinowicz et al. [2002]. In addition, we compared our solution with an independent numerical solution obtained by a finite element software package FEniCS (http://fenicsproject.org/)—-the results of both methods (not shown here) agree within the line thickness.

\section{Water Transport in a Partially Molten Ice Layer}

To quantify the water transport process in a partially molten ice layer, we first solve the equations for a two-phase mixture in a domain composed only of temperate ice (equations (1) and (8)-(10) together with the constitutive equations (4), (5), and (12)). As an initial condition, we consider the porosity profile with maximum at a depth of about $2 \mathrm{~km}$ (black line in Figure 2a):

$$
\phi(d, 0)=\frac{135 d}{81+d^{4}} \%,
$$

where $d=D-z$ is the depth in kilometers. The volumetric heating $H$ is neglected in the reference simulation and the melting temperature is considered uniform. Melting is still possible due to the frictional heating (last 
(a)

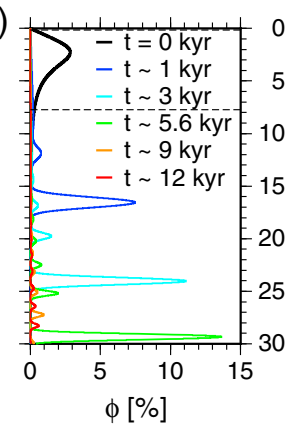

(b)

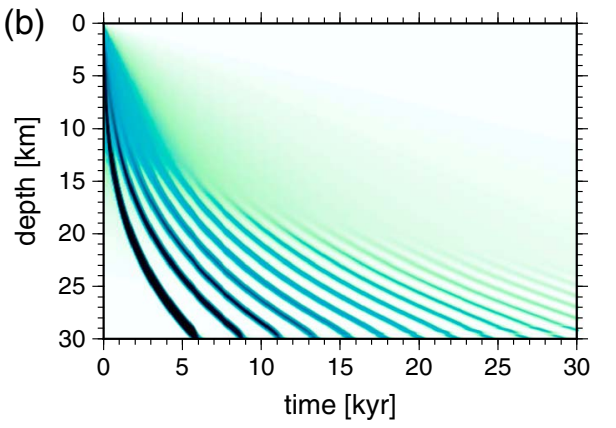

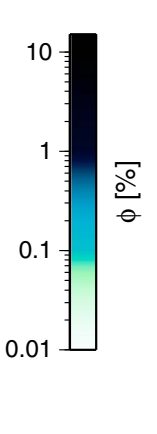

Figure 2. (a) Evolution of porosity in selected time instants (colored lines) obtained for parameters from Table 1. The initial porosity profile is plotted in black. Dashed line marks the border of the subsurface region. (b) Space-time evolution of porosity in a partially molten ice layer for the same set of parameters.

term in equation (10)). The viscosity of the ice matrix $\mu_{\mathrm{m}}$ as well as the other material properties are assumed to be constant as they depend primarily on the temperature.

The time evolution of porosity profiles is computed for the set of parameters from Table 1 and depicted in Figure $2 \mathrm{~b}$. The initial porosity peak propagates downward in the form of successive waves, formed due to the coupling between the fluid motion and the matrix deformation. Their wavelength is controlled by the ice viscosity $\mu_{\mathrm{m}}$ and by the permeability constant $k_{0}$-the higher the value of $\mu_{\mathrm{m}}$ and/or $k_{0}$, the larger the compaction length, equation (21), and thus the larger the wavelength of the waves [Rabinowicz et al., 2002].

The total amount of water in the ice shell (water column height, i.e., porosity integrated throughout the domain) drops each time a wave reaches the bottom boundary (cf. Figure 3a). The first porosity wave containing about $75 \%$ of the total water volume arrives at the bottom approximately 6 kyr after the beginning of the simulation. After only $\sim 15 \mathrm{kyr}$, less than $10 \%$ of the initial water content remains in the ice shell. As indicated in Figure $3 \mathrm{~b}$, the maximum porosity in the subsurface region (uppermost $8 \mathrm{~km}$ ) rapidly decays due to the efficient downward propagation of the porosity waves. The maximum porosity in this region drops below $1 \%$ after only 250 years, indicating that a large volume of water is not sustainable inside a fully temperate region.

The time needed to extract $1 / e$ of the initial amount of water from the layer of thickness $D$ can be estimated using the compaction timescale [McKenzie, 1989]:

$$
t_{\mathrm{D}}=\frac{D \mu_{\mathrm{f}} \phi}{k(\phi) \Delta \rho g}=\frac{D \mu_{\mathrm{f}}}{k_{0} \phi \Delta \rho g},
$$

where the second equality can be obtained by substituting for permeability $k(\phi)$ from equation (5). For $D=30 \mathrm{~km}$ and porosity of the order of few tenths of percent (the average porosity at the beginning of the simulation is $\sim 0.39 \%$ ) this formula yields extraction times of a few kiloyears, which is in good agreement with the time of 6 kyr obtained from Figure 3.

According to equation (25), the time needed to extract a substantial amount of water from the temperate ice layer does not depend on the ice viscosity. This is in agreement with the results of our simulations (not

(a)

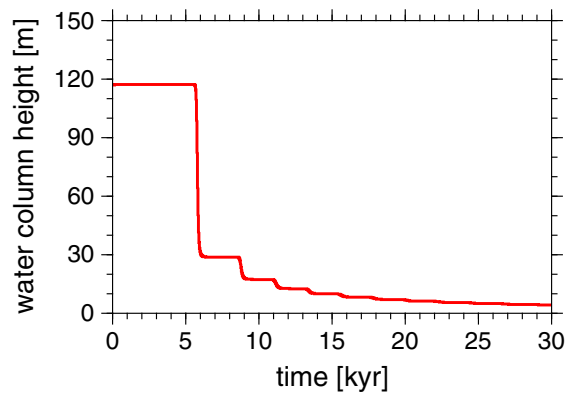

(b)

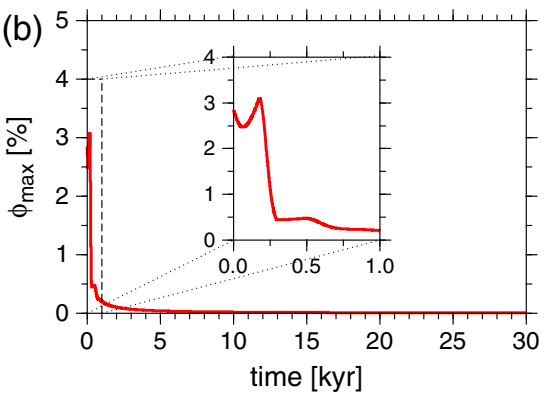

Figure 3. (a) Time evolution of water column height (porosity integrated throughout the domain). (b) Time evolution of maximum porosity in the subsurface region (uppermost $8 \mathrm{~km}$ ). Computed for the set of parameters from Table 1. 
(a)

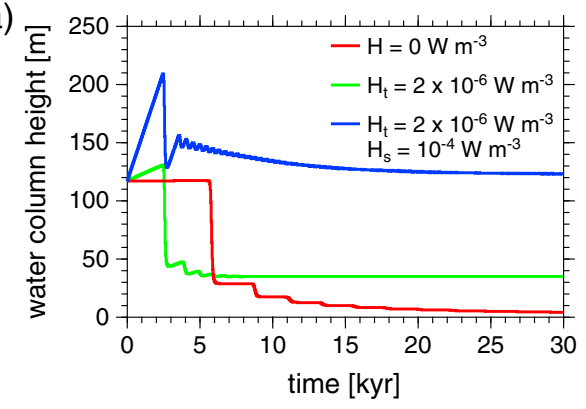

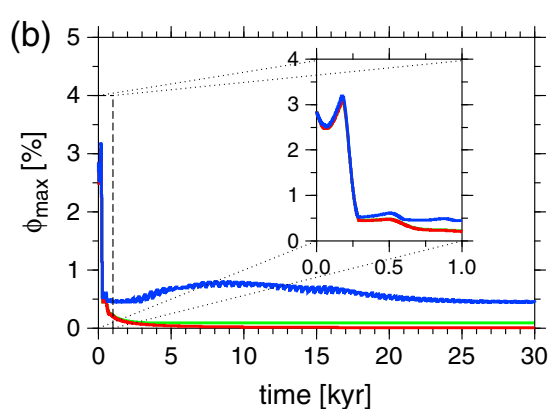

Figure 4. Effect of tidal volumetric $\left(H_{\mathrm{t}}\right)$ and localized shear $\left(H_{\mathrm{s}}\right)$ heating. Red line corresponds to the results obtained for the simulation without heating (the same as in Figure 3). Green line corresponds to the results for volumetric heating only $\left(H=H_{\mathrm{t}}\right)$, whereas blue line displays the results for combined volumetric and localized shear heating $\left(H=H_{\mathrm{t}}+H_{\mathrm{s}}\right)$. (a) Time evolution of water column height. (b) Time evolution of maximum porosity in the subsurface region.

shown here) from which we obtain the travel times of the first waves of about $5 \mathrm{kyr}$ for $\mu_{\mathrm{m}}=10^{13} \mathrm{~Pa}$ s and about $7 \mathrm{kyr}$ for $\mu_{\mathrm{m}}=10^{15} \mathrm{~Pa}$ s. On the other hand, equation (25) implies that the value of the permeability constant $k_{0}$ should affect the extraction timescale substantially, which is again confirmed in our simulations with $k_{0}=10^{-8} \mathrm{~m}^{2}$ and $k_{0}=10^{-10} \mathrm{~m}^{2}$ giving the leading wave travel times of $0.6 \mathrm{kyr}$ and $50 \mathrm{kyr}$, respectively (not shown here). Our simulations with different values of ice viscosity and permeability also confirm the increase of wavelength with increasing $\mu_{\mathrm{m}}$ and/or $k_{0}$ and vice versa (cf. discussion above).

We have also tested the effect of volumetric heating (caused e.g., by tidal dissipation) and localized heating (e.g., due to lateral motions on a strike-slip fault). These results are displayed in Figure 4. The volumetric heating of $2 \times 10^{-6} \mathrm{~W} \mathrm{~m}^{-3}$ (cf. section 4.1.1) reduces the time needed for the first wave to arrive at the bottom more than twice (2.5 kyr instead of $6 \mathrm{kyr}$ ). This is in agreement with equation (25) as the melting in the whole volume increases porosity and thus reduces the porosity wave travel time. Adding a localized source of heat imposed in the uppermost $3 \mathrm{~km}$ influences the overall amount of molten water in the ice shell but has negligible effect on the porosity wave travel time (Figure 4a). The extraction of water from the subsurface layer is still quite efficient and the maximum porosity in that region drops below $1 \%$ again within 250 years for all the studied cases (Figure $4 b$ ).

\section{Polythermal Ice Layer}

When tidally induced melting occurs at shallow depths, the underlying ice is not necessarily at the melting point. In this case, the downward extraction of the melt produced in the region with enhanced heating is delayed and efficient extraction occurs only once the melting point is reached below this domain. In this section, we consider two different geophysical contexts which we implement by imposing specific initial temperature profiles and heating scenarios.

The first one corresponds to melting in the head of a hot plume (hot plume setup, section 4.1.1, after Sotin et al. [2002]), while in the second one the melt is produced by shear motions on a strike-slip fault (strike-slip fault setup, section 4.1.2, after Nimmo and Gaidos [2002]). In regions where the melting point is not reached, the material behaves as cold ice, porosity is zero and the evolution is governed by equations (13)-(15). Once the melting point is reached, ice becomes temperate, melting is enabled and the system must be described by the full set of two-phase equations (1), (4), (5) and (8)-(12). Whether melting occurs in the bulk or not, the top boundary always stays cold due to the fixed surface temperature, which implies that the porosity boundary condition (20) is automatically satisfied. In terms of boundary conditions, the system is thus described by equations (16)-(19).

Viscosity of ice depends in general on numerous factors such as temperature, strain rate, water content etc. [Durham et al., 2001; Goldsby and Kohlstedt, 2001; De La Chapelle et al., 1999]. Although in the cold ice strong viscosity variations can be expected, e.g., in thermal boundary layers or in the vicinity of localized thermal sources, their effect cannot be manifested in our 1-D formalism, as we do not consider any shear deformation and viscous compaction in cold ice (equation (13)). In the temperate ice, the effect of temperature on viscosity is negligible $\left(T=T_{\mathrm{M}}\right)$, however, the influence of porosity (water content) can be significant. The role of ice viscosity on the transport properties in temperate ice was tested and we found that the value of 
viscosity does strongly influence the wavelength of the porosity waves, but its effect on the water-extraction timescale is almost negligible (cf. section 3 and equation (25)). Since our main goal is the estimate of this timescale, for the sake of simplicity, we consider a constant value of viscosity in our simulations.

Besides viscosity, the other crucial parameter is the ice permeability, which was shown to have a major effect on the speed of the porosity waves propagation (cf. section 3 and equation (25)). Since we are interested in the upper estimate for the water-extraction time which determines the stability of the water reservoirs, we choose the minimum admissible value $\left(k_{0}=10^{-10} \mathrm{~m}^{2}\right.$, cf. Figure 1$)$ of the ice permeability constant.

\subsection{Heating Scenarios}

4.1.1. Hot Plume Setup

Since we cannot properly model thermal evolution of a hot plume in one-dimensional geometry, we must approximate it by choosing a suitable parameterization of the heat source. In the context of subsurface water generation, it is crucial to describe the relatively short period in the plume evolution when melting starts to occur in the plume head [e.g., Sotin et al., 2002; Tobie et al., 2003; Běhounková et al., 2010]. The temperature evolution is governed by equation (15) in which the source term includes the combined effect of tidal heating $H_{\mathrm{t}}$ and convection cooling $H_{\text {cool }}$. According to the numerical simulations of Tobie et al. [2003], the total heating rate $H_{\mathrm{t}}-H_{\text {cool }}$ is typically equal to $10-20 \%$ of the tidal heating rate, which allows the following parameterization in terms of a scaling parameter $x$ :

$$
H=H_{\mathrm{t}}-H_{\text {cool }}=x H_{\mathrm{t}} \text {. }
$$

Following Tobie et al. [2003] the viscosity-dependent tidal heating can be expressed as

$$
H_{\mathrm{t}}=\frac{2 H_{\mathrm{t}}^{0}}{\mu_{\mathrm{m}} / \mu_{\mathrm{m}}^{0}+\mu_{\mathrm{m}}^{0} / \mu_{\mathrm{m}}},
$$

where $H_{\mathrm{t}}^{0}=5 \times 10^{-6} \mathrm{~W} \mathrm{~m}^{-3}$ is the average estimate of the heating due to tides and $\mu_{\mathrm{m}}^{0}$ is the ice viscosity at the melting point.

The role of matrix viscosity on the dynamics of polythermal ice has been discussed above-we concluded that using a constant value does not affect the water-extraction time. However, when the effect of viscosity on tidal heating is concerned, the temperature and porosity dependence cannot be neglected. Here we choose the following parameterization:

$$
\mu_{\mathrm{m}}=\mu_{\mathrm{m}}^{0} \exp \left(-\frac{E_{\mathrm{a}}\left(T-T_{\mathrm{M}}^{0}\right)}{R\left(T_{\mathrm{M}}^{0}\right)^{2}}\right) \exp \left(-\gamma_{\mathrm{m}} \phi\right),
$$

where $E_{\mathrm{a}}$ is the activation energy, $R$ is the universal gas constant, and $T_{\mathrm{M}}^{0}$ is the melting temperature at the bottom of the ice shell. The exponential terms in equation (28) describe the temperature and porosity effects, respectively [cf. Tobie et al., 2003]. The value of $\gamma_{\mathrm{m}}$ is chosen so that the increase of porosity by $5 \%$ induces viscosity decrease by 1 order of magnitude [De La Chapelle et al., 1999; Tobie et al., 2003]. The initial temperature profile, which is also estimated from Tobie et al. [2003], and the initial heating profiles for several values of $x$ are shown in Figure 5 .

\subsubsection{Strike-Slip Fault Setup}

This setup represents the process of melt production due to tidally induced displacement along a strike-slip fault. In addition to the volumetric tidal heating $H_{\mathrm{t}}$ (equation (27)), we also include a localized heat source corresponding to shear heating along and just below a strike-slip fault [Nimmo and Gaidos, 2002]. The layer is assumed to be in a conductive state (no convective cooling, $x=1$ ). The initial temperature profile corresponds to the conductive steady state obtained for temperature boundary conditions (equation (16)) and the volumetric tidal heating source $H_{t}$ (equation (27)).

At the beginning of the simulation, shear-heating rate $H_{s}^{0}$ (the values adapted from Nimmo and Gaidos [2002]) is imposed throughout a shear zone of depth $d_{s}$. The initial temperature profile and the corresponding heating for various values of shear zone depth $d_{s}$ and shear-heating amplitude $H_{s}^{0}$ are depicted in Figure 6. Once melting occurs, shear heating is expected to decrease rapidly due to reduction of the friction coefficient [Oksanen and Keinonen, 1982]. Assuming that this reduction is similar as in the case of ice viscosity $\mu_{\mathrm{m}}$, we parameterize it in the same way as in equation (28) [cf. Tobie et al., 2003]:

$$
H_{\mathrm{s}}(d)=H_{\mathrm{s}}^{0} \exp \left(-\gamma_{\mathrm{s}} \phi\right) \quad d \leq d_{\mathrm{s}},
$$



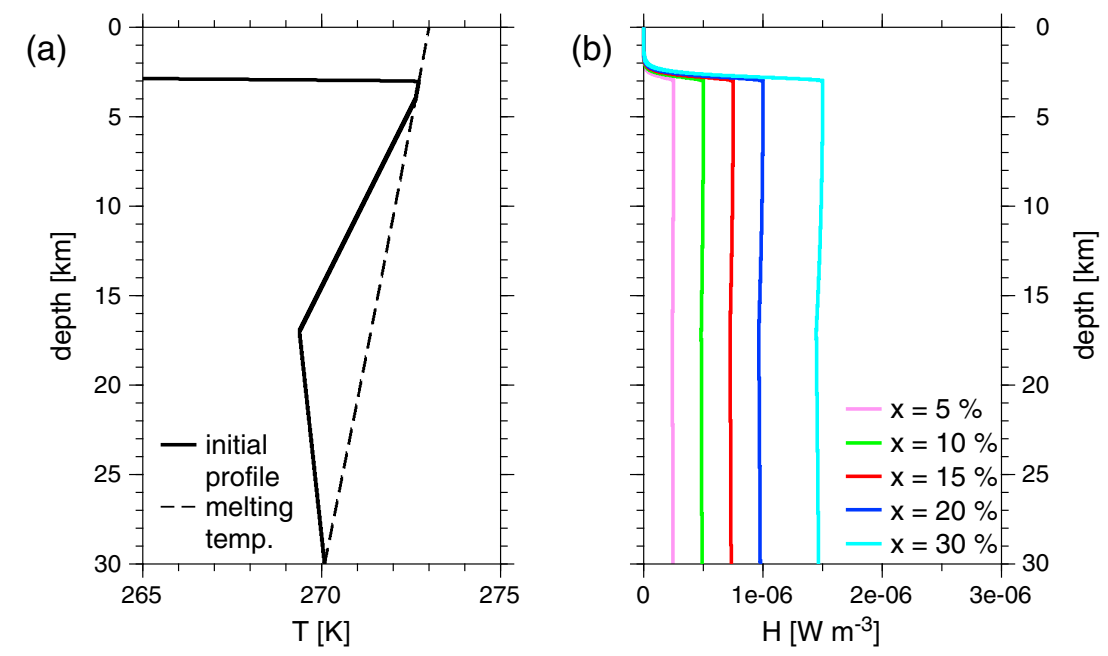

Figure 5. Hot plume setup. (a) Melting temperature and initial temperature profile. (b) Initial heating computed from equations (26) to (28) for different values of $x$ and for the initial temperature profile shown in Figure 5a. Spatial variations are due to temperature dependence of viscosity used in evaluating the heating term (equation (27)).

where $d_{s}$ is the shear zone depth and $\gamma_{s}$ is a weakening parameter. Due to the lack of knowledge, we assume $\gamma_{\mathrm{s}}=\gamma_{\mathrm{m}} \doteq 45$ in the reference solution and vary its value later.

\subsection{Results}

\subsubsection{Hot Plume Setup}

The results for the hot plume simulation with $x=15 \%$ and the model parameters given in Table 1 are depicted in Figure 7. At the beginning of the simulation, the melting temperature is reached only at the bottom boundary and melting just occurs at the base of the ice shell-the water produced there is transported almost immediately to the underlying ocean. The molten (temperate) region where water can propagate spreads gradually from the bottom boundary to the head of the plume. As long as the porosity profile is monotonic with maximum at the bottom boundary, porosity waves do not form (cf. conditions for shock wave formation in Spiegelman [1993a]). At approximately $90 \mathrm{kyr}$, melting begins also at the depth of about $10 \mathrm{~km}$ and porosity waves start to develop. However, their migration is limited within the temperate ice region where temperature is at the melting point. Roughly 40 kyr later $(130 \mathrm{kyr}$ after the beginning of the simulation), both temperate regions connect, thus permitting an efficient transport of water in the partially
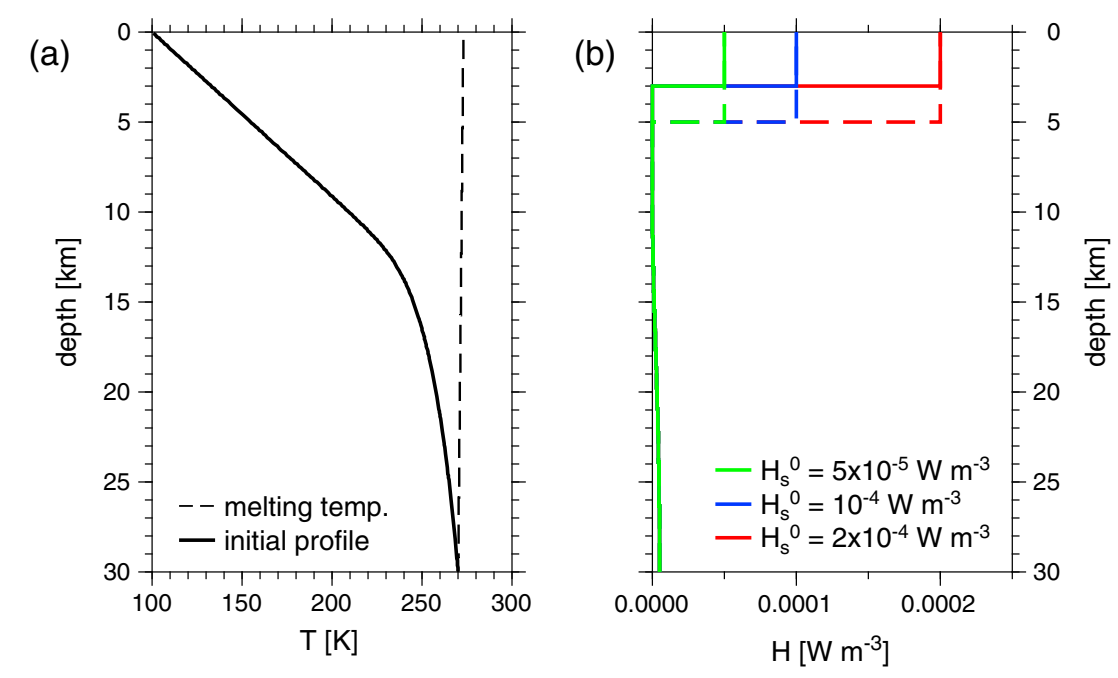

Figure 6. Strike-slip fault setup. (a) Melting temperature and initial temperature profile. (b) Initial heating computed as $H=H_{\mathrm{t}}+H_{\mathrm{s}}$ from equations (26) to (29) for $x=1$, the initial temperature profile shown in Figure 6a and three different values of $H_{\mathrm{s}}^{0}$ (distinguished by different colors). Two values of $d_{\mathrm{s}}$ are considered $d_{\mathrm{s}}=3 \mathrm{~km}$ (full lines) and $d_{\mathrm{s}}=5 \mathrm{~km}$ (dashed lines). 

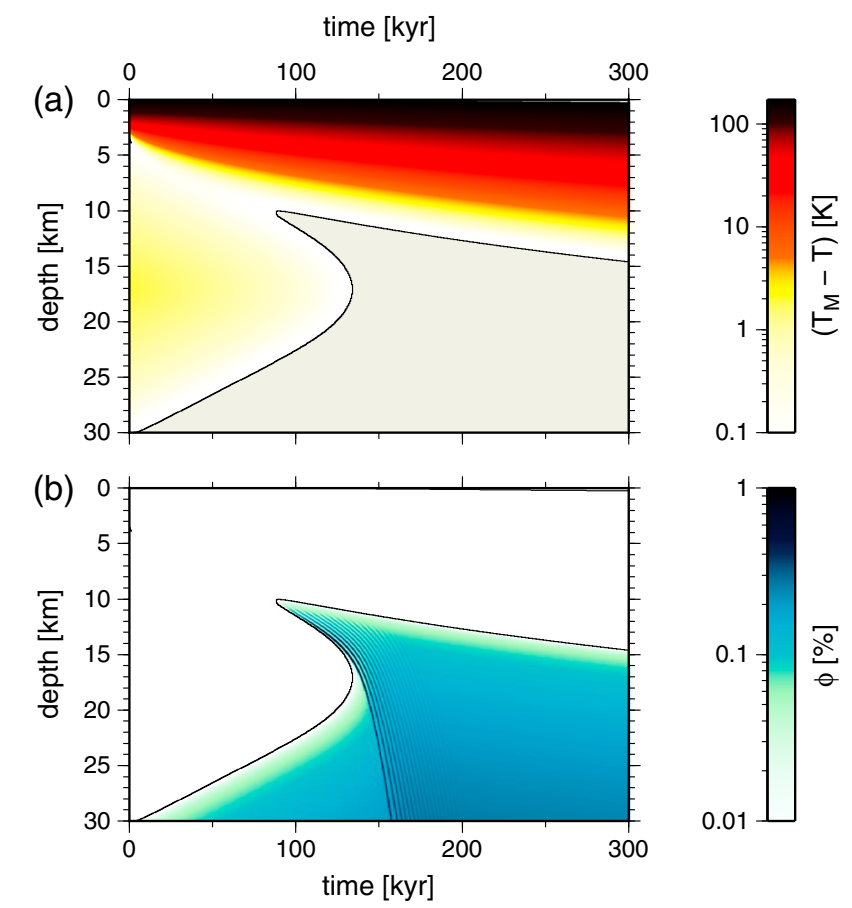

Figure 7. Hot plume setup, $x=15 \%$. (a) Space-time evolution of $T_{M}-T$. (b) Space-time evolution of porosity. The shaded region in Figure $7 \mathrm{a}$ (corresponding to the colored region in Figure $7 \mathrm{~b}$ ) marks the partially molten material at the melting temperature (temperate ice). In both panels, the black line represents the boundary between the temperate ice (with nonzero porosity and temperature at the melting point, thus enabling downward water transport) and the cold ice (with zero porosity, temperature below the melting point and no water transport).

molten zone all the way to the bottom boundary (Figure 7a). Melting temperature is reached in approximately two thirds of the ice shell but the value of porosity never exceeds $1 \%$ (Figure $7 \mathrm{~b}$ ). The outflow of liquid water from the domain is associated with a small subsidence of the top boundary-after $300 \mathrm{kyr}$ of simulation, the thickness of the computational domain is reduced by $\sim 250 \mathrm{~m}$ due to the combined effect of matrix melting and water outflow from the domain.

The total amount of liquid water in the domain as a function of time is shown in Figure 8a (red color). It gradually grows from zero up to a maximum value of about $35 \mathrm{~m}$, which is reached at the time just before the first porosity wave arrives at the bottom boundary ( $160 \mathrm{kyr})$. From that moment, the water outflow is more efficient than the water production and the overall amount of water in the ice shell gradually decreases. At the end of the simulation, a $25 \mathrm{~m}$ high water column still remains in the ice shell; however, the water is distributed over the whole temperate domain and porosity never exceeds $1 \%$ (Figure 7b).

The detail of the time evolution of the maximum value of porosity $\phi$ in the subsurface region (top $4 \mathrm{~km}$ ) is illustrated in Figure $8 \mathrm{~b}$ (red color). The maximum values of porosity remain very small, indicating that all the
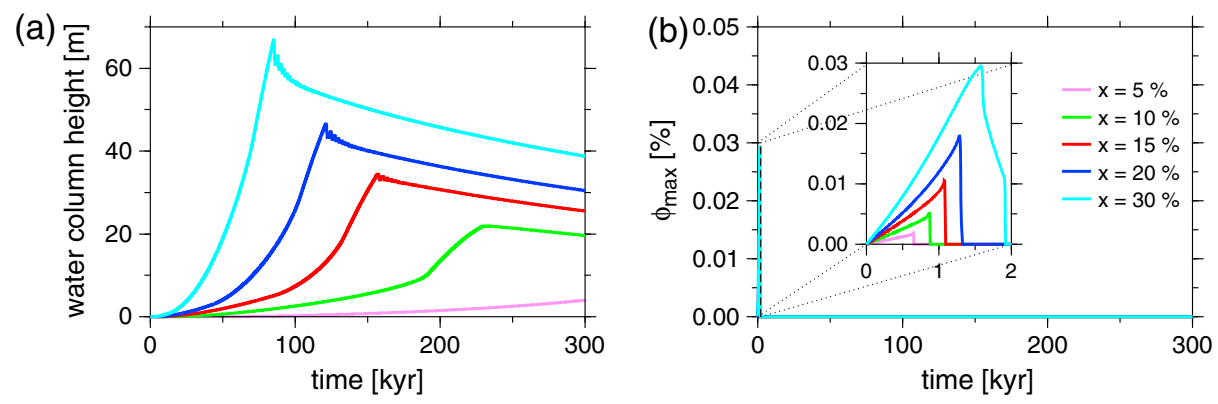

Figure 8. Hot plume setup, results for different values of $x$. (a) Time evolution of the water column height. (b) Time evolution of porosity maximum in the subsurface region (top $4 \mathrm{~km}$ ). 


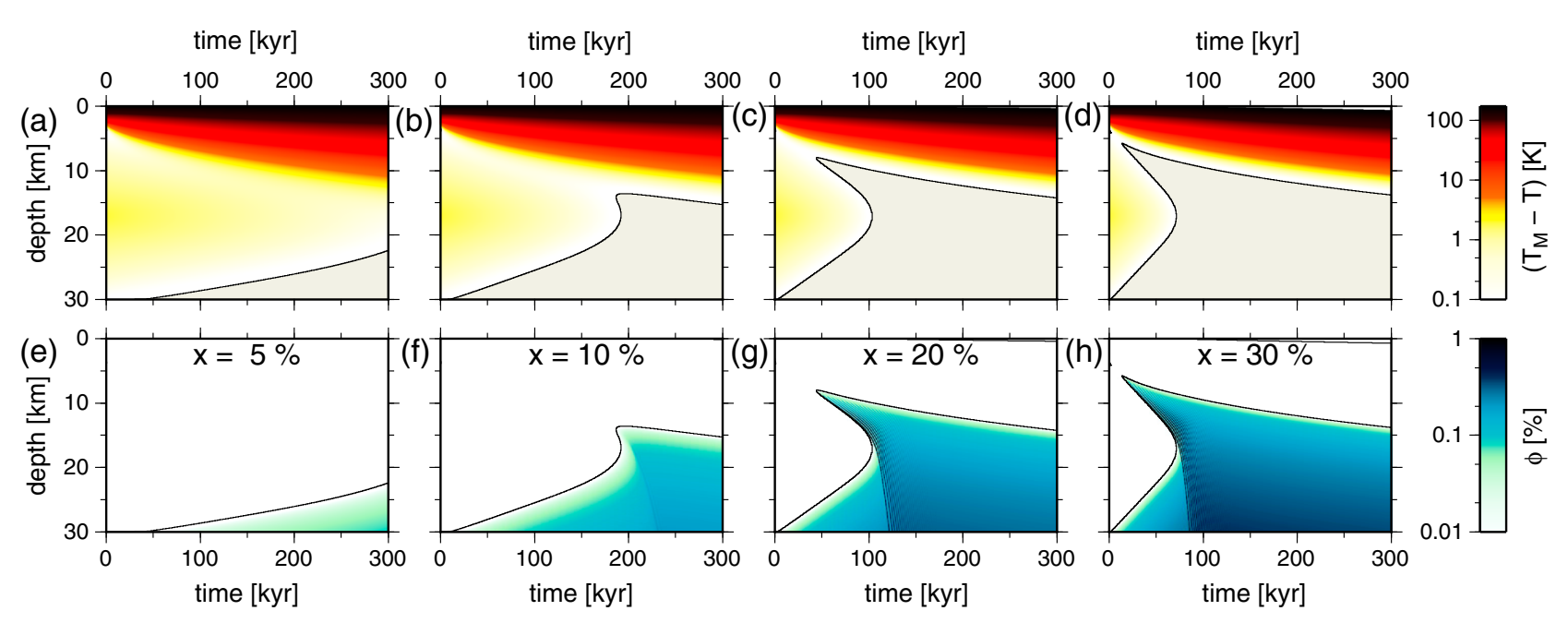

Figure 9. The same as in Figure 7 but for $x=5,10,20$, and 30\% (from left to right).

water produced at shallow depths never accumulates there and is transported very efficiently downward to the internal water ocean.

For higher values of $x$ (20\% and $30 \%$ ), which correspond to less efficient convection and thus more efficient warming of the ice shell, the two distinct melting regions form again (Figures $9 c, 9 d, 9 g$, and $9 h$ ). Since the tidal heating rate is higher, melting starts earlier and more water is produced (Figure 8a, blue and cyan color). On the other hand, both regions coalesce earlier permitting water outflow already at approximately $120 \mathrm{kyr}$ and $85 \mathrm{kyr}$, respectively. When the value of $x$ is decreased to $10 \%$, corresponding to enhanced convective cooling and slower warming of the ice shell, melting occurs only in the lower half of the ice shell (Figures $9 \mathrm{~b}$ and $9 \mathrm{f}$ ) and less water is produced (Figure 8a, green color). For an even smaller value of $x(5 \%)$ melting occurs only at the base of the ice shell during the whole simulation (Figures $9 \mathrm{a}$ and 9e), resulting in a very small amount of water produced (Figure 8a, violet color). For all tested values of $x$, the maximum porosity at shallow depths stays well below $1 \%$ and thus no water accumulates there (Figure $8 b$ ). To summarize, either no melt is produced in the subsurface region at all due to insufficient heating ( $x=5$ and 10\%), or both the subsurface and bottom temperate regions become connected within a few tens of thousands of years, allowing rapid water transport toward the bottom boundary.

\subsubsection{Strike-Slip Fault Setup}

The results for the strike-slip fault simulation with $H_{\mathrm{s}}^{0}=2 \times 10^{-4} \mathrm{~W} \mathrm{~m}^{-3}, d_{\mathrm{s}}=3 \mathrm{~km}$, and $\gamma_{\mathrm{s}}=45$ are displayed in Figure 10 (for the values of other parameters see Table 1). As in the previous section, first melt appears at the bottom boundary and the water flows freely from the domain to the underlying ocean without creating waves. After approximately $90 \mathrm{kyr}$, melting begins also at a depth of about $2 \mathrm{~km}$ where the melting temperature is reached due to the enhanced shear heating. Since the ice below is cold ( $T \ll T_{\mathrm{M}}$, Figure 10a) and assumed free of fractures, no water propagates downward. Even though the heating in the subsurface temperate ice region decreases rapidly due to the increasing porosity ( 1 order of magnitude reduction per $5 \%$ of porosity increase, Figure 10b), the liquid water is trapped there and its amount gradually grows (Figure 10c). As the initial temperature in the upper half of the ice shell is rather low and the volumetric heating (equation (27)) is not very efficient there, the cold impermeable zone separating the subsurface water lens from the bottom temperate zone is preserved throughout the simulation ( $300 \mathrm{kyr})$. A closer inspection of the upper right corner of Figure $10 \mathrm{~b}$ reveals that at the end of simulation the thickness of the domain is reduced by $1 \mathrm{~km}$, which is mostly due to the matrix melting in the shallow region.

The time evolution of water column height is depicted in Figure 11a (red color, full line). With its maximum reaching almost $600 \mathrm{~m}$, the amount of water produced in the strike-slip fault model is much larger than in the previous hot plume model. Figure $11 \mathrm{~b}$ shows the maximum value of porosity within the shear zone $\left(d \leq d_{s}\right)$. Once melting starts, it grows rapidly—after approximately 50 kyr it exceeds $95 \%$ and stays above this value during the rest of the simulation. As discussed in section 5 , our calculations do not take into account possible initiations of Rayleigh-Taylor instabilities due to accumulation of dense liquids above ice or 

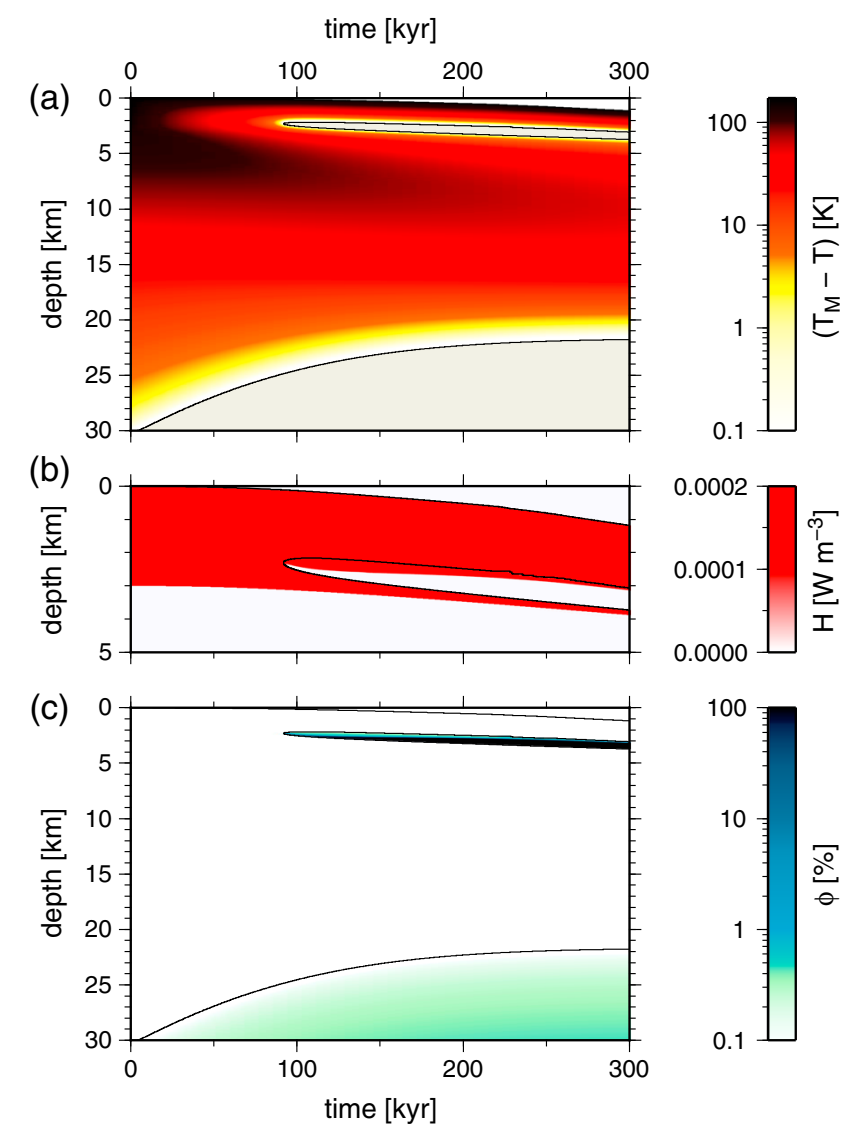

Figure 10. Strike-slip fault setup, $H_{\mathrm{s}}^{0}=2 \times 10^{-4} \mathrm{~W} \mathrm{~m}^{-3}, d_{\mathrm{s}}=3 \mathrm{~km}$, and $\gamma_{\mathrm{s}}=45$. (a) Space-time evolution of $T_{\mathrm{M}}-T$. (b) Space-time evolution of the heating rate in the top $5 \mathrm{~km}$. (c) Space-time evolution of porosity. The shaded regions in Figure 10a (corresponding to the colored regions in Figure 10c) mark the partially molten material at the melting temperature (temperate ice). As in Figure 7, the black lines represent the boundary between the temperate ice and the cold ice. The reduction of the domain thickness is apparent in right upper corners of all panels.

initiation and propagation of water-filled cracks. Consequently, the amounts of water predicted here should be considered as upper limits.

Figure 11 also illustrates the role of the shear-heating amplitude, $H_{s^{\prime}}^{0}$ and the shear zone depth, $d_{s}$. For small shear-heating amplitude $\left(H_{\mathrm{s}}^{0}=5 \times 10^{-5} \mathrm{~W} \mathrm{~m}^{-3}\right)$, no melt is produced at shallow depths (at least during $300 \mathrm{kyr})$ independently of the shear zone depth $d_{s}$. For moderate amplitude of heating $\left(H_{\mathrm{s}}^{0}=10^{-4} \mathrm{~W} \mathrm{~m}^{-3}\right)$ and deeper shear zone $\left(d_{\mathrm{s}}=5 \mathrm{~km}\right)$ a liquid water lens is created and remains stable for at least $100 \mathrm{kyr}$, but no water is produced for the same amplitude of heating and a more shallow shear zone $\left(d_{\mathrm{s}}=3 \mathrm{~km}\right)$.

(a)

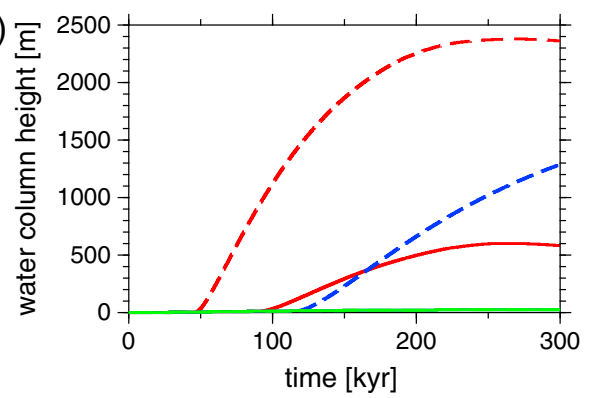

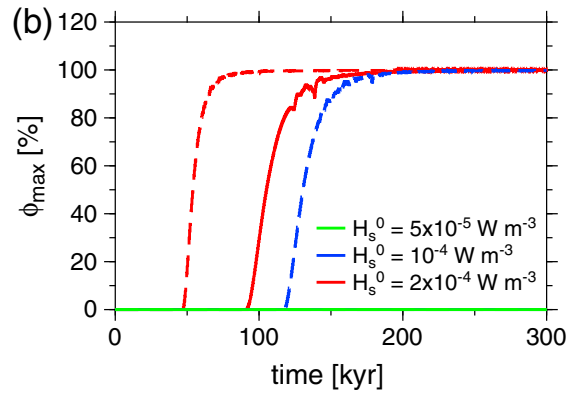

Figure 11. Strike-slip fault setup, results for various combinations of $H_{\mathrm{s}}^{0}$ (distinguished by colors) and $d_{\mathrm{s}}$ (full lines $d_{\mathrm{s}}=3 \mathrm{~km}$ and dashed lines $d_{\mathrm{s}}=5 \mathrm{~km}$ ). (a) Time evolution of the water column height. (b) Time evolution of porosity maximum within the shear zone. 
Increasing further the heating amplitude $H_{\mathrm{s}}^{0}=2 \times 10^{-4} \mathrm{~W} \mathrm{~m}^{-3}$ enables melting also for a more realistic shear zone depth $d_{\mathrm{s}}=3 \mathrm{~km}$ [cf. Nimmo and Gaidos, 2002]. The slight oscillations in Figure $11 \mathrm{~b}$ are caused by a coupling between the temperature and porosity evolution. As the temperature just below the partially molten layer increases, the ice becomes temperate and hence water permeable. Therefore, the water from above can flow downward in the form of waves, since, in this case, porosity decreases in the direction of flow. Consequently, the maximum value of porosity is temporarily reduced due to redistribution of the liquid water over a wider layer of temperate ice.

Our numerical simulations indicate (not shown in Figure 11) that the above results are not affected by varying the value of the porosity weakening parameter $\gamma_{s}$ (equation (29)). This parameter can slightly change the total amount of molten water but has a negligible effect on the maximum porosity in the shear zone and no effect on the thermal evolution of the cold ice layer below and thus does not influence the timescale of the extraction of liquid water from shallow depths.

\section{Discussion}

All our calculations assume a pure water system. The observations of colored hydrated materials within disrupted surface areas suggest that the ice shell may contain a significant fraction of contaminants [e.g., McCord et al., 1998; Kargel et al., 2000; Zolotov and Kargel, 2009]. Low-eutectic constituents such as chloride salts, which are expected within the internal ocean [Zolotov and Kargel, 2009], could lower the melting point by several tens of Kelvins [Kargel et al., 2000; Pappalardo and Barr, 2004]. If these contaminants were uniformly distributed within the ice shell, the reduction of melting point would be uniform and the results should not be significantly different. The presence of contaminants would have a larger impact if they were located only in the upper part of the ice shell. In this case, concentrated brines might form at shallow depths and accumulate at the base of this enriched crust if the underlying ice is cold and contaminant-free, as suggested by Schmidt et al. [2011]. In this context, the volume of the accumulated salty water above a hot plume may be larger than in the case of a pure water system. However, for reasonable salt contents $(1-2 \mathrm{wt} \%)$, the volume fraction of brines should probably not exceed 5-10\%. Further modeling efforts are, however, needed to quantify more precisely the role of low-eutectic constituents.

Our model is clearly limited by its 1-D geometry. Only the vertical matrix deformation associated with compaction is included, and no lateral variations in water production and matrix properties can be treated. The inclusion of lateral variations may change the results by focusing the water extraction into the warmest part of the ice shell (in the center of a hot plume). Moreover, in our 1-D approach, we cannot take into account the ice flow associated with buoyancy variations. In the hot plume case, for instance, we cannot consider the effect of upwelling ice velocity. According to the simulations of Tobie et al. [2003], the velocities in hot plumes are of the order of $3 \times 10^{-8} \mathrm{~m} \mathrm{~s}^{-1}$ for Rayleigh numbers of about $5 \times 10^{6}$, before melting initiates. For a moderate value of permeability constant $\left(k_{0}=10^{-9} \mathrm{~m}^{2}\right)$, the velocity of downward percolating water is at least 4 times larger than the upwelling velocity. Both velocities are comparable only for the lower bound value $\left(k_{0}=10^{-10} \mathrm{~m}^{2}\right.$, cf. Figure 1$)$. In this context, the upwelling velocity may inhibit melt extraction. However, as shown in Tobie et al. [2003], the upwelling velocities are strongly reduced when meltwater is not efficiently extracted, leading eventually to downwelling of the molten plumes even when water fraction reaches values as low as $1-2 \%$. The extension into $2-D$ or $3-D$ geometry will be needed to properly describe the lateral flows and the development of convective instabilities.

Similarly, a 2-D/3-D approach is necessary to describe the destabilization of large volume of water accumulated below a shear zone or at the base of a salt-rich crust above a hot plume. The accumulation of dense liquids above an impermeable cold ice layer should lead to the development of Rayleigh-Taylor instabilities, which cannot be properly described in our 1-D approach. According to the analytical description of Whitehead and Luther [1975], the time required to destabilize a dense water reservoir above an ice layer is longer than $10 \mathrm{kyr}$ only for ice viscosities larger than $10^{22} \mathrm{~Pa}$ s. Such high viscosity values are possible only for temperatures lower than $160 \mathrm{~K}$, which implies that large volumes of water can be present at shallow depths only in the case of a cold conductive layer subjected to very intense localized heating.

Furthermore, our model neglects the effect of hydrofracturing, possibly relevant in the strike-slip fault setup. On the Earth, crevasse hydrofracturing has been shown to allow a very rapid drainage of supraglacial lakes toward the glacier base [cf. Krawczynski et al., 2009; Irvine-Fynn et al., 2011]. As discussed in section 1, differences in physical settings make direct comparison between the Earth and Europa system questionable. 
On Europa, the best candidate environment for nucleation and propagation of water-filled cracks would be in cold ice regions beneath a large volume of accumulated water (similar to what we obtain in the strike-slip fault setup). A strong effect counterbalancing this mechanism would, however, be the fast freezing of water in such a cold environment (typically several tens of Kelvins below the melting point in our results for the strike-slip fault setup). The corresponding closure rate depends on the crack geometry and water supply rate and its inclusion would require additional effort [cf. Michaut and Manga, 2014].

Both Rayleigh-Taylor instabilities and hydrofracturing processes may become predominant only once a sufficient volume of water is accumulated. Further modeling is needed to evaluate the critical volume for which these processes dominate in Europa's ice shell conditions and to understand how they differ from those on the Earth. In any case, once activated, these processes would reduce the amount of accumulated water, and therefore, the volumes reported here should be considered as upper limits.

\section{Conclusions}

In the present study, we investigated the conditions under which water can be generated and transported by downward two-phase flow within Europa's ice shell. A two-phase mixture model was developed in a 1-D framework, distinguishing two possible states: temperate (partially molten ice, with some amount of interstitial water) and cold (purely solid ice below the melting point).

In the case of purely temperate ice, our simulations show that water is transported downward in the form of successive porosity waves. Our results confirm that the time of water transport through the ice shell is mainly controlled by the ice permeability while the volumetric heating is a second-order effect. The porosity wavelength is influenced by the ice permeability and viscosity. Overall, the water propagation through a temperate ice shell is quite efficient: we show that the time needed to transport substantial amount of water from the subsurface region to the underlying ocean varies between about $10^{\circ}$ and $10^{2} \mathrm{kyr}$ for reasonable values of ice permeability.

We then considered two distinct geophysical contexts possibly leading to melting at shallow depths within Europa's ice shell. Our simulations show that water produced in the head of a tidally heated hot plume is rapidly extracted (within less than a few hundred kiloyears) and no water accumulates at shallow depths-the maximum porosity never exceeds $1 \%$. In contrast, in the context of a fault subjected to tidally induced strike-slip motions, a large fraction of water can accumulate just below the fault, as long as the underlying ice layer remains cold, conductive, and free of fractures. Our models indicate that complete melting is soon achieved in a layer a few kilometers below the surface for a shear-heating rate of at least $10^{-4} \mathrm{~W} \mathrm{~m}^{-3}$. Our calculations suggest that a fault must be active during at least $100 \mathrm{kyr}$ and associated with a periodic strike-slip motions with the shear velocities of about $10^{-7}-10^{-6} \mathrm{~m} \mathrm{~s}^{-1}$ [Nimmo and Gaidos, 2002] in order to initiate significant melting. The water production and accumulation below the shear zone might explain the formation of water sills advocated by Dombard et al. [2013] as a necessary ingredient to produce the morphology of Europa's ubiquitous double ridges.

Acknowledgments

The authors would like to thank Francis Nimmo and two anonymous referees for many useful comments which helped to improve the manuscript. This research received funding from the European Research Council under the European Community's Seventh Framework Programme FP7/2007-2013 grant agreement 259285 and the project LL1202 in the programme ERC-CZ funded by the Ministry of Education, Youth and Sports of the Czech Republic. K.K. acknowledges the support from the Charles University grant SVV-2013-267308. O.S. is a junior researcher in the University Center for Mathematical Modelling, Applied Analysis and Computational Mathematics (Math MAC) of Charles University in Prague.
Overall, despite some simplifications in the water transport description, our simulations showed that accumulation of a significant water volume above warm ice plumes is very unlikely, whereas it may be temporarily possible below recently active double ridges subjected to large strike-slip motions. Transient water accumulation ( $\leq 100 \mathrm{kyr}$ ) and drainage may play a key role in the dynamics of Europa's ice shell and may be revealed by future exploration missions [Grasset et al., 2013; Pappalardo et al., 2013]. Future modeling will help to understand the consequences of water accumulation and transport in terms of mass and heat transfer through the ice shell, as well as their surface expression.

\section{References}

Anderson, J. D., G. Schubert, R. A. Jacobson, E. L. Lau, W. B. Moore, and W. L. Sjogren (1998), Europa's differentiated internal structure: Inferences from four Galileo encounters, Science, 281(5385), 2019-2022, doi:10.1126/science.281.5385.2019.

Barr, A. C., and R. T. Pappalardo (2005), Onset of convection in the icy Galilean satellites: Influence of rheology, J. Geophys. Res., 110, E12005, doi:10.1029/2004JE002371.

Barr, A. C., and A. P. Showman (2009), Heat transfer in Europa's icy shell, in Europa, edited by R. T. Pappalardo, W. B. McKinnon, and K. Khurana, pp. 405-430, The University of Arizona Press, Tucson.

Běhounková, M., G. Tobie, G. Choblet, and O. Čadek (2010), Coupling mantle convection and tidal dissipation: Applications to Enceladus and Earth-like planets, J. Geophys. Res., 115, E09011, doi:10.1029/2009JE003564.

Běhounková, M., G. Tobie, G. Choblet, and O. Čadek (2012), Tidally-induced melting events as the origin of south-pole activity on Enceladus, Icarus, 219(2), 655-664, doi:10.1016/j.icarus.2012.03.024. 
Bercovici, D., Y. Ricard, and G. Schubert (2001), A two-phase model for compaction and damage: 1. General theory, J. Geophys. Res., 106(B5), 8887-8906, doi:10.1029/2000JB900430.

Bierhaus, E. B., K. Zahnle, and C. R. Chapman (2009), Europa's crater distributions and surface ages, in Europa, edited by R. T. Pappalardo, W. B. McKinnon, and K. Khurana, pp. 161-180, Univ. Arizona Press, Tucson, Ariz.

Birchwood, R. A., and D. L. Turcotte (1994), A unified approach to geopressuring, low-permeability zone formation, and secondary porosity generation in sedimentary basins, J. Geophys. Res., 99(B10), 20,051-20,058, doi:10.1029/93JB02388.

Carr, M. H., et al. (1998), Evidence for a subsurface ocean on Europa, Nature, 391(6665), 363-365, doi:10.1038/34857.

Chizhov, V. E. (1993), Thermodynamic properties and thermal equation of state of high-pressure ice phases, Prikl. Mekh. Tekhn. Fiz., 2, 113-123.

Collins, G., and F. Nimmo (2009), Chaotic terrain on Europa, in Europa, edited by R. T. Pappalardo, W. B. McKinnon, and K. Khurana, pp. 259-281, Univ. Arizona Press, Tucson, Ariz.

Connolly, J. A. D., and Y. Y. Podladchikov (2007), Decompaction weakening and channeling instability in ductile porous media: Implications for asthenospheric melt segregation, J. Geophys. Res., 112, B10205, doi:10.1029/2005JB004213.

Crawford, G. D., and D. J. Stevenson (1988), Gas-driven water volcanism and the resurfacing of Europa, Icarus, 73(1), 66-79, doi:10.1016/0019-1035(88)90085-1.

De La Chapelle, S., H. Milsch, O. Castelnau, and P. Duval (1999), Compressive creep of ice containing a liquid intergranular phase: Rate-controlling processes in the dislocation creep regime, Geophys. Res. Lett., 26(2), 251-254, doi:10.1029/1998GL900289.

Dombard, A. J., G. W. Patterson, A. P. Lederer, and L. M. Prockter (2013), Flanking fractures and the formation of double ridges on Europa, Icarus, 223(1), 74-81, doi:10.1016/j.icarus.2012.11.021.

Drew, D. A. (1971), Averaged field equations for two-phase media, Stud. Appl. Math., 50(2), 133-166.

Drew, D. A. (1983), Mathematical modeling of two-phase flow, Annu. Rev. Fluid Mech., 15, 261-291, doi:10.1146/annurev.fl.15.010183.001401.

Durham, W. B., L. A. Stern, and S. H. Kirby (2001), Rheology of ice I at low stress and elevated confining pressure, J. Geophys. Res., 106(6), 11031-11042, doi:10.1029/2000JB900446.

Eicken, H., H. R. Krouse, D. Kadko, and D. K. Perovich (2002), Tracer studies of pathways and rates of meltwater transport through Arctic summer sea ice, J. Geophys. Res., 107(C10), 8046, doi:10.1029/2000JC000583.

Fountain, A. G., and J. S. Walder (1998), Water flow through temperate glaciers, Rev. Geophys., 36(3), 299-328, doi:10.1029/97RG03579.

Freitag, J. (1999), The hydraulic properties of Arctic sea ice: Implications for the small-scale particle transport [in German], Ber. Polarforsch., 325, 150.

Freitag, J., and H. Eicken (2003), Meltwater circulation and permeability of Arctic summer sea ice derived from hydrological field experiments, J. Glaciol., 49(166), 349-358, doi:10.3189/172756503781830601.

Gaidos, E. J., and F. Nimmo (2000), Tectonics and water on Europa, Nature, 405(6787), 637, doi:10.1038/35015170.

Golden, K. M., S. F. Ackley, and V. I. Lytle (1998), The percolation phase transition in sea ice, Science, 282(5397), 2238-2241, doi:10.1126/science.282.5397.2238.

Golden, K. M., A. L. Heaton, H. Eicken, and V. I. Lytle (2006), Void bounds for fluid transport in sea ice, Mech. Mater., 38(8-10), 801-817, doi:10.1016/j.mechmat.2005.06.015.

Golden, K. M., H. Eicken, A. L. Heaton, J. Miner, D. J. Pringle, and J. Zhu (2007), Thermal evolution of permeability and microstructure in sea ice, Geophys. Res. Lett., 34, L16501, doi:10.1029/2007GL030447.

Goldsby, D. L., and D. L. Kohlstedt (2001), Superplastic deformation of ice: Experimental observations, J. Geophys. Res., 106(B6), 11017-11030, doi:10.1029/2000JB900336.

Grasset, O., et al. (2013), Jupiter Icy moons Explorer (JUICE): An ESA mission to orbit Ganymede and to characterise the Jupiter system, Planet. Space Sci, 78, 1-21, doi:10.1016/j.pss.2012.12.002.

Gusmeroli, A., T. Murray, P. Jansson, R. Pettersson, A. Aschwanden, and A. D. Booth (2010), Vertical distribution of water within the polythermal Storglaciären, Sweden, J. Geophys. Res., 115, F04002, doi:10.1029/2009JF001539.

Hock, R. (2005), Glacier melt: A review of processes and their modelling, Prog. Phys. Geog., 29(3), 362-391, doi:10.1191/0309133305pp453ra.

Irvine-Fynn, T. D. L., A. J. Hodson, B. J. Moorman, G. Vatne, and A. L. Hubbard (2011), Polythermal glacier hydrology: A review, Rev. Geophys., 49, RG4002, doi:10.1029/2010RG000350.

Kargel, J. S., J. Z. Kaye, J. W. Head III, G. M. Marion, R. Sassen, J. K. Crowley, O. P. Ballesteros, S. A. Grant, and D. L. Hogenboom (2000), Europa's crust and ocean: Origin, composition, and the prospects for life, Icarus, 148(1), 226-265, doi:10.1006/icar.2000.6471.

Kattenhorn, S. A., and T. Hurford (2009), Tectonics of Europa, in Europa, edited by R. T. Pappalardo, W. B. McKinnon, and K. Khurana, pp. 199-236, Univ. Arizona Press, Tucson, Ariz.

Kawamura, T., M. Ishikawa, T. Takatsuka, S. Kojima, and K. Shirasawa (2006), Measurements of permeability of sea ice, Proceedings of the 18th IAHR International Symposium on Ice, 105-112, Sapporo, Japan.

Kivelson, M. G., K. K. Khurana, C. T. Russell, M. Volwerk, R. J. Walker, and C. Zimmer (2000), Galileo magnetometer measurements: A stronger case for a subsurface ocean at Europa, Science, 289(5483), 1340-1343, doi:10.1126/science.289.5483.1340.

Krawczynski, M. J., M. D. Behn, S. B. Das, and I. Joughin (2009), Constraints on the lake volume required for hydro-fracture through ice sheets, Geophys. Res. Lett., 36, L10501, doi:10.1029/2008GL036765.

Lliboutry, L. (1996), Temperate ice permeability, stability of water veins and percolation of internal meltwater, J. Glaciol., 42(141), 201-211.

Manga, M., and C.-Y. Wang (2007), Pressurized oceans and the eruption of liquid water on Europa and Enceladus, Geophys. Res. Lett., 34, L07202, doi:10.1029/2007GL029297.

McCord, T. B., et al. (1998), Salts on Europa's surface detected by Galileo's near infrared mapping spectrometer, Science, 280(5367), 1242-1245, doi:10.1126/science.280.5367.1242.

McKenzie, D. (1984), The generation and compaction of partially molten rock, J. Petrol., 25(3), 713-765.

McKenzie, D. (1989), Some remarks on the movement of small melt fractions in the mantle, Earth Planet. Sci. Lett., 95(1-2), 53-72, doi:10.1016/0012-821X(89)90167-2.

McKinnon, W. B. (1999), Convective instability in Europa's floating ice shell, Geophys. Res. Lett., 26(7), 951-954, doi:10.1029/1999GL900125.

Michaut, C., and M. Manga (2014), Domes, pits and small chaos on Europa produced by water sills, J. Geophys. Res. Planets, 119, doi:10.1002/2013JE004558.

Nimmo, F., and E. Gaidos (2002), Strike-slip motion and double ridge formation on Europa, J. Geophys. Res., 107(E4), 5021, doi:10.1029/2000JE001476.

Nimmo, F., and B. Giese (2005), Thermal and topographic tests of Europa chaos formation models from Galileo E15 observations, Icarus, 177(2), 327-340, doi:10.1016/j.icarus.2004.10.034. 
Oksanen, P., and J. Keinonen (1982), The mechanism of friction of ice, Wear, 78(3), 315-324, doi:10.1016/0043-1648(82)90242-3.

Olson, P., and U. Christensen (1986), Solitary wave propagation in a fluid conduit within a viscous matrix, J. Geophys. Res., 91(B6), 6367-6374, doi:10.1029/JB091iB06p06367.

Pappalardo, R. T., et al. (1998), Geological evidence for solid-state convection in Europa's ice shell, Nature, 391(6665), 365-368, doi:10.1038/34862.

Pappalardo, R. T., et al. (1999), Does Europa have a subsurface ocean? Evaluation of the geological evidence, J. Geophys. Res., 104(EI0), 24015-24055, doi:10.1029/1998JE000628.

Pappalardo, R. T., and A. C. Barr (2004), The origin of domes on Europa: The role of thermally induced compositional diapirism, Geophys. Res. Lett., 31, L01701, doi:10.1029/2003GL019202.

Pappalardo, R. T., et al. (2013), Science from the Europa clipper mission concept: Exploring the habitability of Europa, European Planetary Science Congress, London (UK), EPSC Abstracts Vol. 8, EPSC2013-886.

Petrich, C., P. J. Langhorne, and Z. F. Sun (2006), Modelling the interrelationships between permeability, effective porosity and total porosity in sea ice, Cold Reg. Sci. Technol., 44(2), 131-144, doi:10.1016/j.coldregions.2005.10.001.

Petrich, C., and H. Eicken (2009), Growth, structure and properties of sea ice, in Sea Ice, edited by D. N. Thomas and G. S. Dieckmann, pp. 23-77, Wiley-Blackwell, Chichester, U. K.

Rabinowicz, M., Y. Ricard, and M. Grégoire (2002), Compaction in a mantle with a very small melt concentration: Implications for the generation of carbonatitic and carbonate-bearing high alkaline mafic melt impregnations, Earth Planet. Sci. Lett., 203(1), 1205-220, doi:10.1016/S0012-821X(02)00836-1.

Ricard, Y., D. Bercovici, and G. Schubert (2001), A two-phase model for compaction and damage: 2. Applications to compaction, deformation, and the role of interfacial surface tension, J. Geophys. Res., 106(B5), 8907-8924, doi:10.1029/2000JB900431.

Ricard, Y., O. Šrámek, and F. Dubuffet (2009), A multi-phase model of runaway core-mantle segregation in planetary embryos, Earth Planet. Sci. Lett., 284(1-2), 144-150, doi:10.1016/j.epsl.2009.04.021.

Schmidt, B. E., D. D. Blankenship, G. W. Patterson, and P. M. Schenk (2011), Active formation of chaos terrain over shallow subsurface water on Europa, Nature, 479(7374), 502-505, doi:10.1038/nature10608.

Scott, D. R., and D. J. Stevenson (1984), Magma solitons, Geophys. Res. Lett., 11(11), 1161-1164, doi:10.1029/GL011i011p01161.

Scott, D. R., D. J. Stevenson, and J. A. Whitehead (1986), Observations of solitary waves in a viscously deformable pipe, Nature, 319(6056), 759-761, doi:10.1038/319759a0.

Scott, D. R., and D. J. Stevenson (1989), A self-consistent model of melting, magma migration and buoyancy-driven circulation beneath mid-ocean ridges, J. Geophys. Res., 94(B3), 2973-2988, doi:10.1029/JB094iB03p02973.

Showman, A. P., I. Mosqueira, and J. W. Head III (2004), On the resurfacing of Ganymede by liquid-water volcanism, Icarus, 172(2), 625-640, doi:10.1016/j.icarus.2004.07.011.

Shu, C.-W. (1998), Essentially non-oscillatory and weighted essentially non-oscillatory schemes for hyperbolic conservation laws, in Advanced Numerical Approximation of Nonlinear Hyperbolic Equations, Lecture Notes in Mathematics, vol. 1697, edited by A. Quarteroni, pp. 325-432, Springer-Verlag, Berlin, Heidelberg.

Simon, F., and G. Glatzel (1929), Bemerkungen zur schmelzdruckkurve, Z. Annorg. Allg. Chem., 178(1), 309-316, doi:10.1002/zaac.19291780123.

Sotin, C., J. W. Head III, and G. Tobie (2002), Europa: Tidal heating of upwelling thermal plumes and the origin of lenticulae and chaos melting, Geophys. Res. Lett., 29(8), 1233, doi:10.1029/2001GL013844.

Spiegelman, M., and D. McKenzie (1987), Simple 2-D models for melt extraction at mid-ocean ridges and island arcs, Earth Planet. Sci. Lett., 83(1-4), 137-152, doi:10.1016/0012-821X(87)90057-4.

Spiegelman, M. (1993a), Flow in deformable porous media I: Simple analysis, J. Fluid Mech., 247, 17-38, doi:10.1017/S0022112093000369.

Spiegelman, M. (1993b), Flow in deformable porous media II: Numerical analysis-The relationship between shock waves and solitary waves, J. Fluid Mech., 247, 39-63, doi:10.1017/S0022112093000370.

Šrámek, O., Y. Ricard, and D. Bercovici (2007), Simultaneous melting and compaction in deformable two-phase media, Geophys. J. Int., 168(3), 964-982, doi:10.1111/j.1365-246X.2006.03269.x.

Šrámek, O., Y. Ricard, and F. Dubuffet (2010), A multiphase model of core formation, Geophys. J. Int., 181(1), 198-220, doi:10.1111/j.1365-246X.2010.04528.x.

Tobie, G., G. Choblet, and C. Sotin (2003), Tidally heated convection: Constraints on Europa's ice shell thickness, J. Geophys. Res., 108(E11), 5124, doi:10.1029/2003JE002099.

Whitehead, J. A., and D. S. Luther (1975), Dynamics of laboratory diapir and plume models, J. Geophys. Res., 80(5), 705-717, doi:10.1029/JB080i005p00705.

Zolotov, M. Y., and J. S. Kargel (2009), On the composition of Europa's icy shell, ocean and underlying rocks, in Europa, edited by R. T. Pappalardo, W. B. McKinnon, and K. Khurana, pp. 431-457, Univ. Arizona Press, Tucson, Ariz. 